\title{
Debido proceso e independencia judicial en América Latina
}

\author{
Arnel Medina-Cuenca* \\ Ernesto Salcedo-Ortega ${ }^{* *}$ \\ Omar Huertas-Díaz ${ }^{\star * *}$
}

Vicedecano de la Facultad de Derecho, Universidad de La Habana, Cuba. Correo electrónico:

arnelmedinacuenca@yahoo.es

* Profesor titular de Teoría General del Proceso, Universidad Católica de Santiago de Guayaquil, Ecuador.

Correo electrónico:

ernesto.salcedo.o@gmail.com

*** PH.D. en Ciencias de la Educación, Universidad Simón Bolívar, Barranquilla, Colombia.

Correo electrónico:

ohuertasd@unal.edu.co

Recibido: 6 de febrero del 2017

Aprobado: 27 de marzo del 2017

Cómo citar este artículo: Arnel MedinaCuenca, Ernesto Salcedo-Ortega, Omar Huertas-Díaz. Debido proceso e independencia judicial en América Latina. DIXI 26. Mayo 2017. Pág. 37. doi: http://dx.doi. org/10.16925/di.v19i26.1950

\section{Resumen}

Introducción: la independencia judicial constituye una garantía del debido proceso y uno de los presupuestos esenciales para el mejor funcionamiento del poder judicial. Metodología: el estudio de una garantía que impide la injerencia de los otros poderes en la resolución de los asuntos sometidos al conocimiento de jueces y tribunales se aborda por medio del estudio de los principales instrumentos jurídicos internacionales, las constituciones y leyes nacionales, así como del análisis de casos resueltos por la jurisprudencia nacional y la Corte Interamericana de Derechos Humanos. Resultados y conclusiones: asuntos tales como la forma de elección de los jueces y magistrados, la duración del mandato, las evaluaciones de su desempeño y las injerencias externas en su actuación, se abordan desde diferentes enfoques doctrinales, y también desde el derecho comparado, con el objetivo de medir el grado de confianza del pueblo en su sistema judicial, como parte fundamental de la democracia.

Palabras clave: Corte Interamericana, debido proceso, garantías, imparcialidad, independencia judicial, poder judicial. 


\title{
Due Process and Judicial Independence in Latin America
}

\begin{abstract}
Introduction: Judicial independence constitutes a guarantee of due process and one of the essential assumptions for the better operation of the judicial power. Methods: The study of a guarantee that prevents the interference of the other powers in the resolution of matters submitted to the knowledge of judges and courts is addressed by examining the main international legal instruments, constitutions and national laws, as well as the analysis of cases resolved by the national case law and the Inter-American Court of Human Rights. Results and conclusions: Issues such as how judges and magistrates are elected, the duration of their office, performance evaluations and external interference in their actions are approached from both doctrinal approaches and comparative law, aiming at measuring the degree of people's confidence in their judicial system, as a fundamental part of democracy.
\end{abstract}

Keywords: Inter-American Court, due process, guarantees, impartiality, judicial independence, judicial power. 


\section{INTRODUCCIÓN ${ }^{1}$}

La administración de justicia, en particular los organismos encargados de hacer cumplir la ley $y$ del enjuiciamiento así como un poder judicial $y$ una abogacía independientes, en plena conformidad con las normas contenidas en los instrumentos internacionales de derechos humanos, son de importancia decisiva para la cabal realización de los derechos humanos sin discriminación alguna y resultan indispensables en los procesos de democratización y desarrollo sostenible.

Declaración y Programa de Acción de Viena, 1993

En la actualidad, la independencia judicial constituye uno de los postulados más importantes para la consecución de los derechos humanos fundamentales, una garantía indiscutible del debido proceso que ya ha sido conquistada, en lo fundamental, en los instrumentos jurídicos internacionales y en las constituciones y leyes nacionales de América Latina. Sin embargo, avanza muy lentamente y con numerosos escollos en estas áreas geográficas y también con significativas diferencias entre países.

En la región latinoamericana, los poderes judiciales usualmente se han caracterizado por los bajos niveles de independencia judicial. En la mayoría de los países, en algunos de sus contextos históricos, han estado sometidos a diversos tipos de presiones y controles por parte de los poderes ejecutivos y legislativos. Los altos magistrados de los consejos de judicatura tampoco se han caracterizado por ser los mejores veladores y defensores de la independencia judicial reconocida legalmente.

Después de poco más de un siglo, los poderes judiciales de la región han sido un apéndice de los poderes ejecutivos, de manera que, en la actualidad, los ordenamientos jurídicos de casi todos los países latinoamericanos procuran una mayor institucionalización y aplicación de la independencia judicial. En las últimas décadas, el poder judicial ha adquirido mayor protagonismo, dada su influencia en el desarrollo de las democracias y su incidencia en la política económica de estos pueblos, y por el deseo de alcanzar seguridad jurídica, todo ello en el contexto de los sistemas de cooperación internacional.

1. Artículo de investigación desarrollado en el marco de la colaboración entre los Grupos de Investigación "Escuela de Derecho Penal Nullum Crimen Sine Lege un", reconocido y clasificado en A por Colciencias 2015, la Facultad de Derecho de la Universidad de la Habana y la Universidad Católica de Santiago de Guayaquil.
En los tiempos actuales, existe en este entorno geográfico una mayor comprensión de cómo la justicia depende de la independencia de los operadores de justicia que intervienen en el pleito. Por ello, es preciso comprender la independencia como garantía del proceso judicial, con la cual se puede obtener un proceso limpio, justo, expedito y transparente. Como garantía, apunta Díez-Picazo, la independencia judicial es un conjunto de mecanismos jurídicos tendientes a la salvaguardia y realización del mencionado valor, si bien este también se protege por medio de otros principios que, en rigor, son diferentes de la independencia judicial (división de poderes, juez natural, imparcialidad y exclusividad, entre otros). El principal problema por resolver en el ámbito del derecho constitucional es el de la independencia como garantía, por lo que puede decirse que es esta la independencia judicial stricto sensu. ${ }^{2}$

Es, por tanto, un axioma incuestionable el hecho de que la independencia judicial constituye uno de los presupuestos esenciales para el mejor funcionamiento del poder judicial. Se trata de una garantía que impide la injerencia de los otros poderes en la resolución de litigios sometidos a su conocimiento, la cual, además, da como resultado la confianza del pueblo como parte fundamental de la democracia.

La independencia judicial, como garantía de un debido proceso, ${ }^{3}$ debe analizarse desde una doble perspectiva: como independencia institucional del poder judicial en su conjunto, frente a injerencias externas de poderes fácticos u otros poderes del Estado, y como independencia funcional, la cual se encarna en los jueces para resolver conflictos conforme al derecho y libres de toda presión, aliciente o injerencia indebida.

Como se analizará más adelante, la independencia institucional del poder judicial exige como garantías la facultad de autogobierno, la autarquía, la dotación de recursos suficientes y la implementación de procesos adecuados y transparentes para la designación oportuna y en propiedad de los jueces y magistrados, incluyendo la Corte Suprema de Justicia. ${ }^{4}$ El

2. Véase Luis María Diez-Picazo. Notas de derecho comparado sobre la independencia judicial. Revista EsPañola DE DeReCho Constitucional 34. Año 12. Enero-Abril 1992. Pág. 21.

3. Véase Omar Huertas Díaz, Francisco Javier Trujillo Londoño, Luis Gonzalo Lozano Pacheco y José Alfredo Sanabria. EL DERECHO AL DEBIDO PROCESO Y LAS GARANTÍAS JUDICIALES EN LA DIMENSIÓN INTERNACIONAL DE LOS DERECHOS HUMANOS. Grupo Editorial Ibáñez. (2007).

4. Véase Impunity Watch. Programa Guatemala, procesos de elección de magistrados en Guatemala y Honduras. (2015). Disponible en http://www.impunitywatch.org/docs/ 32531_ IMPUNITY_WATCH_Proceso_eleccion_magistrados_GT_y_ HN_TEX-TO.pdf 
informe de Impunity Watch señala, además, cómo el relator especial de Naciones Unidas considera que el presupuesto asignado al poder judicial debe adecuarse a sus necesidades, estar asegurado y revisarse progresivamente, para lo cual debe establecerse un porcentaje fijo del producto interno bruto (РIB) en el marco normativo. ${ }^{5}$

Desde la perspectiva funcional o de la independencia del juez individual, se exige que los procedimientos utilizados para la selección de jueces y magistrados aseguren que serán nombradas personas íntegras e idóneas, y tendrán la formación o las calificaciones jurídicas apropiadas. Todo método utilizado para la selección de personal judicial garantizará que este no se nombre por motivos indebidos. En la selección de los jueces, no se hará discriminación alguna por motivo de raza, color, sexo, religión, opinión política o de otra índole, origen nacional o social, posición económica, nacimiento o condición; el requisito de que los postulantes a cargos judiciales sean nacionales del país del que se trate, no se considerará discriminatorio. ${ }^{6}$

Esta investigación sobre la situación de la independencia judicial en América Latina, procura establecer qué se entiende en la actualidad por independencia y cuáles son los factores que impiden, dentro de la región, facilitar su aplicación y vigencia, así como destacar los principales aportes y fortalezas con que cuentan hoy en día estas naciones para que la función judicial cumpla con su finalidad, esto es, convertirse en una entidad garante de la igualdad, de la dignidad y de los derechos de los seres humanos, base de la democracia y que colabora en el restablecimiento del orden social.

\section{LA INDEPENDENCIA JUDICIAL EN LOS INSTRUMENTOS JURÍDICOS}

\section{INTERNACIONALES Y REGIONALES}

El sistema judicial de un país es esencial para la protección de los derechos humanos y las libertades. Los tribunales cumplen la función fundamental de

\footnotetext{
5. Véase Oficina Naciones Unidas, C. L. INFORME DEL RELATOR ESPECIAL LEANDRO DESPouY SOBRE LA INDEPENDENCIA DE LOS Magistrados y ABogados. A/HrC/11/41. (Marzo 24 de 2009). Disponible en http://www2.ohchr.org/english/bodies/hrcouncil/ docs/11session/A.HRC.11.41_sp.pdf

6. Véase Naciones Unidas. Oficina de las Naciones Unidas contra la Droga y el Delito. Comentario Relativo a los Principios De BANGalore Sobre la CONDUCTA JUdicial. (2013). Disponible en http://www.unodc.org/documents/corruption/Publications/2012/ V1380121-SPAN_eBook.pdf
}

asegurar que las víctimas o potenciales víctimas de violaciones de derechos humanos sean protegidas y obtengan una reparación eficaz, y que los perpetradores de las violaciones a los derechos humanos sean llevados ante la justicia. Asimismo, los tribunales aseguran que cualquier sospechoso de haber cometido un delito reciba un juicio justo, de acuerdo con las normas internacionales, y que tanto el poder ejecutivo como el legislativo actúen de acuerdo con los derechos humanos consagrados internacionalmente y las expectativas del Estado de derecho.

La independencia judicial se constituye como el principio que propende hacia la búsqueda de garantías y condiciones que permitan a la judicatura gozar de las condiciones necesarias para el ejercicio de sus funciones de forma legítima, imparcial, trasparente y eficaz. El poder que reviste la rama judicial para el desarrollo de las dinámicas propias del Estado se ve enmarcado en las garantías constitucionales y legales, así como en las funciones que tiene a su cargo para el establecimiento de un orden social. La correcta administración de justicia, el control de los poderes públicos y la protección de los derechos, entre otras funciones, requieren una judicatura que en la práctica labore libre de vicios y bajo condiciones que permitan un ejercicio legítimo y garante de la democracia. Bajo esta perspectiva, la independencia judicial se constituye como el principio que busca garantías y condiciones que permitan a la judicatura gozar de las condiciones necesarias para el ejercicio de sus funciones de forma legítima, imparcial, trasparente y eficaz.

En el estudio de la independencia judicial, es necesario acudir a importantes instrumentos jurídicos internacionales que crean un marco jurídico de protección a dicha independencia, como, por ejemplo, la Carta Democrática Interamericana, la cual, en su artículo 3 precisa:

Son elementos esenciales de la democracia representativa, entre otros, el respeto a los derechos humanos y las libertades fundamentales; el acceso al poder y su ejercicio con sujeción al Estado de Derecho; la celebración de elecciones periódicas, libres, justas y basadas en el sufragio universal y secreto como expresión de la soberanía del pueblo; el régimen plural de partidos y organizaciones políticas; y la separación e independencia de los poderes públicos. ${ }^{7}$

7. Véase Organización de los Estados Americanos. CARTA Democrática Interamericana. Documentos e interpretaCIONEs. (2003). Pág 3. Disponible en https://www.oas.org/ oaspage/ esp/Publicaciones/CartaDemocratica_spa.pdf 
Asimismo, los principios internacionales sobre la independencia y la responsabilidad de los jueces, abogados y fiscales. ${ }^{8}$

En los principios internacionales se afirma cómo, a pesar de que los jueces, abogados y fiscales gozan de los mismos derechos humanos que las demás personas, también gozan de una protección especial, debido a su papel como garantes de los derechos humanos para el resto de la población. Si los jueces no pueden evaluar los hechos y aplicar la ley, tanto nacional, como internacional, el sistema judicial se vuelve arbitrario. Si los abogados no pueden comunicarse libremente con sus clientes, se viola el derecho a la defensa y el principio de igualdad procesal, el cual exige que ambas partes de un proceso penal sean tratadas de igual manera. Si la integridad física de los fiscales no se protege cuando sus vidas corren peligro a causa de su trabajo, se ve afectado su deber de instituir un proceso. ${ }^{9}$

Sin embargo, esta protección especial implica responsabilidades especiales. El principio de independencia de los jueces no está dirigido a otorgarles beneficios personales; su justificación es proteger a los individuos contra los abusos de poder y garantizar una recta administración de justicia. En consecuencia, los jueces no pueden decidir casos de forma arbitraria, de acuerdo con sus preferencias personales, sino que deben aplicar el derecho a los hechos. ${ }^{10}$

En las primeras tres conclusiones del artículo, el presidente del Tribunal Supremo de la República de Cuba, ${ }^{11}$ considera lo siguiente:

- La concepción tradicional sobre el desempeño de la función judicial se ha enfocado más en asegurar las garantías y derechos de los jueces que de los justiciables, amparándose para ello en la interpretación hipertrofiada sobre la vigencia y el alcance del principio de independencia judicial.

- La vigencia y el alcance del principio de independencia judicial no puede ni debe colisionar con los presupuestos de efectividad del ejercicio de la función judicial, ni con las garantías y los derechos de los justiciables.

8. Cf. Comisión Internacional de Juristas. Principios InterNACIONALES SOBRE LA INDEPENDENCIA Y RESPONSABILIDAD DE JUECES, ABOGADOS Y FISCALES-GUÍA PARA PROFESIONALES. (2005). Disponible en http://hrlibrary.umn.edu/research/peru-Principios $\% 20$ Internacionales $\% 20$ sobre $\% 20$ responsabilidad $\% 20 \mathrm{de} \%$ 20Jueces\%20y\%20\%20Fiscales.pdf

9. Id. Págs. 2 y 3 .

10. Véase Rubén Remigio Ferro. La independencia judicial y la gestión de la calidad en los tribunales. Justicia y Derecho 26. Año 14. 2016. Pág. 16.

11 Id
- La gestión de la calidad es una herramienta conceptual y práctica imprescindible para el ejercicio efectivo de la función judicial, concebida como servicio público, que exige el mejoramiento continuo de su desempeño para satisfacer las necesidades de la sociedad y los ciudadanos, en correspondencia con el contenido de la Constitución y las leyes.

En el caso de los fiscales, su deber es el de investigar e instituir procesos en todos los casos de violación de los derechos humanos, sin perjuicio de quién los haya perpetrado. Los abogados, por su parte, deben en todo momento realizar su trabajo contemplando el interés del cliente. Por lo tanto, jueces, abogados y fiscales son esenciales para la plena vigencia del derecho a un juicio justo. A menos que todos ellos sean capaces de cumplir sus funciones adecuadamente, el Estado de derecho y el derecho a un juicio justo corren grave peligro.

La Organización de las Naciones Unidas, al considerar que la Declaración Universal de Derechos Humanos consagra concretamente el principio de la igualdad ante la ley, el derecho de toda persona a que se presuma su inocencia y el de ser oída públicamente y con justicia por un tribunal competente, independiente e imparcial establecido por la ley, aprobó, en el Séptimo Congreso de las Naciones Unidas sobre Prevención del Delito y Tratamiento del Delincuente, celebrado en Milán del 26 de agosto al 6 de septiembre de 1985, los Principios Básicos relativos a la independencia de la judicatura, que fueron confirmados por la Asamblea General en sus resoluciones 40/32 del 29 de noviembre de 1985, y 40/146 del 13 de diciembre de $1985 .{ }^{12}$ En relación con la independencia de la judicatura, se adoptaron los siguientes principios: 1) la independencia de la judicatura será garantizada por el Estado y proclamada por la Constitución o la legislación del país. Todas las instituciones gubernamentales y de otra índole respetarán y acatarán la independencia de la judicatura; 2) los jueces resolverán los asuntos que conozcan con imparcialidad, basándose en los hechos y en consonancia con el derecho, sin restricción alguna y sin influencias, alicientes, presiones, amenazas o intromisiones indebidas, sean directas o indirectas, de cualesquiera sectores o por cualquier motivo; 3 )

12. Adoptados por el Séptimo Congreso de las Naciones Unidas sobre Prevención del Delito y Tratamiento del Delincuente, celebrado en Milán del 26 de agosto al 6 de septiembre de 1985, y confirmados por la Asamblea General en sus resoluciones 40/32 de 29 de noviembre de 1985 y 40/146 de 13 de diciembre de 1985. Véase A. G. Res. 40/32. (Noviembre 29 de 1985); y A. G. Res. 40/146 (Diciembre 13 de 1985). 
la judicatura será competente en todas las cuestiones de índole judicial y tendrá autoridad exclusiva para decidir si una cuestión que le haya sido sometida está dentro de la competencia que le haya atribuido la ley; 4) no se efectuarán intromisiones indebidas o injustificadas en el proceso judicial, ni se someterán a revisión las decisiones judiciales de los tribunales. Este principio se aplicará sin menoscabo de la vía de revisión judicial ni de la mitigación o conmutación de las penas impuestas por la judicatura efectuada por las autoridades administrativas de conformidad con lo dispuesto en la ley; 5) toda persona tendrá derecho a ser juzgada por los tribunales de justicia ordinarios con arreglo a procedimientos legalmente establecidos. No se crearán tribunales que no apliquen normas procesales debidamente establecidas para sustituir la jurisdicción que corresponda normalmente a los tribunales ordinarios; 6) el principio de la independencia de la judicatura autoriza y obliga a la judicatura a garantizar que el procedimiento judicial se desarrolle conforme a derecho, así como el respeto de los derechos de las partes; 7) cada Estado miembro proporcionará recursos adecuados para que la judicatura pueda desempeñar debidamente sus funciones.

La Conferencia Mundial de Derechos Humanos, celebrada en Viena en 1993, constituyó también un hito en la historia de las Naciones Unidas, con la aprobación de la Declaración y el Programa de Acción de Viena, ${ }^{13}$ el cual fue de gran ayuda para promover los esfuerzos encaminados a lograr la observancia de los principios de la Carta de las Naciones Unidas y de la Declaración Universal de Derechos Humanos, así como en materia de independencia judicial.

En el párrafo 27 de la Declaración, se precisa que cada Estado debe prever un marco de recursos eficaces a fin de reparar las infracciones o violaciones de los derechos humanos. La administración de justicia, en particular los organismos encargados de hacer cumplir la ley y el enjuiciamiento, así como un poder judicial y una abogacía independientes, en plena conformidad con las normas contenidas en los instrumentos internacionales de derechos humanos, son de importancia decisiva para la cabal realización de los derechos humanos sin discriminación alguna y resultan indispensables en los procesos de democratización y desarrollo sostenible. En este contexto, las instituciones que se ocupan de la administración

13. Véase Declaración y Programa de Acción de Viena. Conferencia Mundial de Derechos Humanos. Oficina del Alto Comisionado de las Naciones Unidas para los Derechos Humanos y el Departamento de Información Pública de las Naciones Unidas. (1993). Págs. 1-55. de justicia deben estar adecuadamente financiadas, y la comunidad internacional debe prever un nivel más elevado de asistencia técnica y financiera. Incumbe a las Naciones Unidas establecer con carácter prioritario programas especiales de servicios de asesoramiento, y lograr así una administración de justicia fuerte e independiente. ${ }^{14}$

En el contexto iberoamericano, el estatuto del juez, aprobado por los presidentes de los más altos tribunales de los países de la región, en la vi Cumbre Iberoamericana de presidentes de Cortes Supremas y Tribunales Supremos de Justicia, celebrada en Santa Cruz de Tenerife, Canarias, España, los días 23, 24 y 25 de mayo de 2001, se reconoce en el artículo 1, como Principio general de independencia, "como garantía para los justiciables, los Jueces son independientes en el ejercicio de sus funciones jurisdiccionales y se encuentran tan sólo sometidos a la Constitución y a la ley, con estricto respeto al principio de jerarquía normativa". ${ }^{15}$

En otros artículos del "Estatuto del juez iberoamericano", se reafirman las declaraciones que se presentan a continuación.

Obligación de respeto a la independencia judicial. Los otros poderes del Estado y, en general, todas las autoridades, instituciones y organismos nacionales o internacionales, así como los diferentes grupos y organizaciones sociales, económicos y políticos, deben respetar y hacer efectiva la independencia de la judicatura (Artículo 2).

Independencia judicial y medios de comunicación. La utilización de los medios de comunicación social con el objeto de suplantar funciones jurisdiccionales, imponer o influir el contenido de las resoluciones judiciales, en condiciones que excedan el legítimo derecho a la libertad de expresión e información, se considera lesiva para la independencia judicial (Artículo 3).

Independencia interna. En el ejercicio de la jurisdicción, los jueces no se encuentran sometidos a autoridades judiciales superiores, sin perjuicio de la facultad de estas de revisar las decisiones por medio de los recursos legalmente establecidos, y de la fuerza que cada ordenamiento nacional atribuya a la jurisprudencia y a los precedentes emanados de las Cortes Supremas y Tribunales Supremos (Artículo 4).

Defensa de la independencia judicial. Los atentados a la independencia judicial han de ser

\footnotetext{
14. Id. Pág. 27.

15. Véase Biblioteca Virtual U. Estatuto del juez iberoameriCANo. (2001). Pág. 2. Disponible en http://www.biblioteca.org.ar/ libros/211800.pdf
} 
sancionados por ley, la cual deberá prever los mecanismos por medio de los cuales los jueces inquietados o perturbados en su independencia puedan obtener el respaldo de los órganos superiores o de gobierno del Poder Judicial (Artículo 5).

Condiciones materiales de la independencia. El Estado garantizará la independencia económica del Poder Judicial, mediante la asignación del presupuesto adecuado para cubrir sus necesidades y por medio del desembolso oportuno de las partidas presupuestarias (Artículo 6).

El Tribunal Europeo de Derechos Humanos ha establecido que, como criterios generales para determinar la independencia de un tribunal, se "debe tener en cuenta, inter alia, la forma e integración de sus miembros y su mandato, la existencia de salvaguardas contra presiones externas y la cuestión si tiene apariencia de independiente". ${ }^{16}$

El 27 de julio del 2006, el Consejo Económico y Social de las Naciones Unidas aprobó la Resolución 2006/23, titulada "Fortalecimiento de los principios básicos de la conducta judicial”. En el párrafo 22, se afirma que la independencia judicial no es un privilegio ni una prerrogativa del juez considerado individualmente. Es la responsabilidad impuesta a cada juez para permitirle fallar una controversia en forma honesta e imparcial sobre la base del derecho y de la prueba, sin presiones ni influencias externas y sin temor a la interferencia de nadie. ${ }^{17}$

Los Principios de Bangalore sobre la conducta judicial se incluyeron como anexo del informe presentado por el relator especial sobre la independencia de magistrados y abogados, Dato ParamCumaraswamy, al $59^{\circ}$ periodo de sesiones de la Comisión de Derechos Humanos de las Naciones Unidas. El 29 de abril del 2003, la Comisión aprobó por unanimidad la Resolución 2003/43 que tomó nota de los Principios de Bangalore sobre la conducta judicial y señaló esos principios "a la atención de los Estados Miembros, los órganos de las Naciones Unidas y las organizaciones intergubernamentales y no gubernamentales, para su consideración. ${ }^{18}$

El núcleo central del principio de la independencia judicial es la total libertad del juez para conocer de las causas sometidas al tribunal y fallarlas; nadie

16. Véase Carlos Ayala-Corao. La independencia de la justicia y los procesos constituyentes en la región andina. Estudios Constitucionales 6(1). 2008. Pág. 351. Disponible en http://132.248.9.34/hevila/Estudiosconstitucionales/2008/vol6/ no1/16.pdf

17. Véase Naciones Unidas. Oficina de las Naciones Unidas contra la Droga y el Delito, supra, nota 6. Pág 12.

18. Id. Pág. 10. externo - Gobierno, grupo de presión, persona o incluso otro juez- debe interferir o tratar de interferir en la forma en que el juez sustancia una causa y adopta una decisión. ${ }^{19}$

Los Principios de Bangalore sobre la conducta judicial constituyen un instrumento de gran valor potencial, no solo para los jueces de todas las naciones, sino también para el público en general, así como para todas las personas interesadas en el establecimiento de sólidos cimientos para una judicatura mundial de integridad inobjetable. Han recibido creciente aceptación de parte de los diferentes sectores de la judicatura mundial y de los organismos internaciones interesados en la integridad del proceso judicial. Como resultado de ello, los Principios de Bangalore se perciben cada vez más como un documento que todas las judicaturas y sistemas jurídicos pueden aceptar sin reservas. Las organizaciones internacionales también los han recibido favorablemente y les han dado su respaldo. ${ }^{20}$

El Consejo Económico y Social de las Naciones Unidas, en su Resolución 2006/23 del 27 de julio del 2006, invitó a los Estados miembros, de conformidad con sus ordenamientos jurídicos internos a que, al examinar o elaborar normas con respecto a la conducta profesional y ética de los miembros de la judicatura, tomasen en consideración los Principios de Bangalore. La Oficina de las Naciones Unidas contra la Droga y el Delito ha apoyado activamente los Principios de Bangalore, los cuales también han recibido el reconocimiento de órganos tales como la American Bar Association y la Comisión Internacional de Juristas. Los jueces de los Estados miembros del Consejo de Europa también han acogido favorablemente estos principios. ${ }^{21}$

Lograr acuerdos en torno a estos principios básicos ha sido difícil, pero el irrenunciable compromiso del Grupo de Integridad Judicial de lograr un resultado que pudiese recibir aceptación universal le ha permitido superar las barreras que se alzaron en su camino. Estos principios dan expresión a las más elevadas tradiciones de la función judicial como se la concibe en todas las culturas y sistemas jurídicos. ${ }^{22}$

La ley garantizará la permanencia en el cargo de los jueces por los periodos establecidos, su independencia y su seguridad, así como una remuneración, pensiones y condiciones de servicio y de jubilación adecuadas.
19. Id. Pág. 33.
20. Id.
21. Id.
22. Id. Págs. III y IV. 
Asimismo, se requieren garantías en relación con su seguridad en el cargo hasta la edad de jubilación obligatoria o la expiración de su mandato (seguridad en el puesto), y condiciones que rijan los ascensos, los traslados, la suspensión y la cesación en sus funciones y la seguridad económica.

Un elemento muy interesante de los Principios de Bangalore lo constituye la precisión sobre la razón de que la independencia judicial tenga tanta importancia pública se debe a que una sociedad libre solo existe en la medida en que está regida por el principio de la legalidad, el principio que obliga a gobernantes y gobernados, administrados imparcialmente, y que concede un trato igualitario a todos quienes procuran reparaciones o contra quienes tales reparaciones se procuran. Por muy vaga que se perciba y muy confuso que sea el pensamiento, en los corazones de todos los hombres y mujeres existe una aspiración de legalidad. El cumplimiento de esta aspiración depende de que los jueces apliquen la ley de manera competente e imparcial. Con el fin de cumplir esta responsabilidad, es fundamental que los jueces sean independientes y se les vea como tales. La sociedad se ha acostumbrado a la noción de que la independencia judicial incluye la independencia respecto a los dictados del poder ejecutivo. Sin embargo, las decisiones modernas son tan variadas e importantes que debe propiciarse la independencia con respecto a toda influencia que pueda tender, o que razonablemente pueda pensarse que tienda, a una falta de imparcialidad en la adopción de decisiones. La independencia con respecto al poder ejecutivo es básica para este concepto, pero ha dejado de ser la única independencia que importa. ${ }^{23}$

Si bien los instrumentos jurídicos relacionados y otros muchos más existen, y los principios enunciados en las constituciones y las leyes procesales se corresponden con los aprobados por la comunidad internacional y las organizaciones regionales, se debe reconocer que, a pesar de existir avances en Latinoamérica - sobre todo, de la mano de las reformas judiciales y procesales-, aún falta mucho por hacer, principalmente para que los principios enunciados en las leyes se cumplan con la transparencia que se requiere y así garantizar la plena vigencia de los derechos humanos, la igualdad ante la ley y el humanismo que debe caracterizar a la impartición de justicia, entre otras aspiraciones de los hombres

23. Véase Sir Gerard Brennan. Judicial independence. THн Australian Judicial Conference, noviembre 2 de 1996, Camberra, Australia. Pág. 5. Disponible en http://www.jca.asn.au/wpcontent/uploads/2014/07/P62_02_09-Judicial-Independencefrom-the-Executive-June-2014.pdf y mujeres de buena voluntad que aspiramos a un mundo mejor para todos los seres humanos, en el que el debido proceso se convierta en una realidad.

\section{LA INDEPENDENCIA JUDICIAL EN AMÉRICA LATINA}

Al independizarse, la mayoría de los países de América Latina eligió modelos europeos para elaborar sus constituciones, las cuales reflejaban las estructuras autoritarias que prevalecían en el continente en ese momento. Después de las revoluciones, guerras y reformas ocurridas en Europa, estas estructuras autoritarias fueron modificadas considerablemente. Sin embargo, entre los países latinoamericanos, la mayoría no siguió este camino; el dominio del poder ejecutivo era la regla, y el poder judicial era una rama subsidiaria, muchas veces bajo el declarado control del poder ejecutivo, encargado de garantizar que nada afectara a aquellos en cuyas manos estaba el poder político o económico.

Los jueces percibían salarios excesivamente bajos y carecían de prestigio. Además, muchos países estaban invadidos por la corrupción. Como lo expresó un líder dominicano en 1988: "La justicia es un mercado en donde se venden sentencias". ${ }^{24}$

Los poderes judiciales eran instituciones relativamente marginales dentro del juego político de estos países, con un peso - en términos relativos- bastante menor al de los otros poderes del Estado, y de entidades como la iglesia, los partidos políticos y los sindicatos.

La necesidad de fortalecer la independencia judicial ha sido un aspecto sustancial de las reformas procesales penales en la región. Así, por ejemplo, en la década de los ochenta, como se mencionó antes, en muchos países latinoamericanos el poder judicial se encontraba supeditado a los poderes ejecutivo y legislativo, los cuales mantenían plenas facultades no solo para su designación, sino en ciertos casos hasta para su remoción. Incluso, en ocasiones el tiempo de duración del cargo de un magistrado del máximo Tribunal de Justicia o Corte Suprema, coincidía con el tiempo de duración del periodo presidencial en el que fueron elegidos, lo que revela la influencia de los

24. Véase Victor José Castellanos. INFORME SOBRE INDEPENDencia judicial en la República Dominicana. (2000). Pág. 3. Disponible en http://www.dplf.org/sites/default/files/1184345829. pdf 
políticos de turno en la labor de la administración de justicia.

A fin de salvaguardar la independencia judicial, bastante cuestionada en estos países por aquellos tiempos, algunas naciones decidieron traspasar tradicionales atribuciones de los poderes políticos a la Suprema Corte de Justicia. Sin embargo, los resultados de estos cambios implicaron que los jueces de instancia o inferiores, en lugar de sufrir presiones de autoridades de gobierno o agentes externos, empezaron a soportar las mismas presiones de parte de los estamentos superiores de la propia función judicial, entiéndase de los magistrados de la Corte Suprema. Esto, en razón a que la selección y designación de los jueces de instancia, así como el control de su régimen de disciplina, pasó de manos de los gobiernos de turno, a convertirse en competencia de los integrantes del máximo órgano de justicia de un país.

Lograr mayor independencia judicial es una de las motivaciones fundamentales tras el intenso proceso de reformas que, casi sin excepción, los diversos sistemas judiciales de la región vienen experimentando en los últimos años. Existe ya una extendida conciencia de cómo la independencia judicial no solo es fundamental para una vigencia real del Estado de derecho, sino también para el desarrollo económico y social de los pueblos.

Ante las recurrentes y reiteradas denuncias de ciudadanos y organizaciones sociales representantes de la gran mayoría de países de Latinoamérica, sobre vulneraciones y transgresiones a los derechos humanos y de delitos de lesa humanidad, con grave afectación a la independencia judicial, algunos Estados decidieron instituir comisiones de la verdad con el fin de documentar y procurar una sucinta investigación de todos aquellos casos que trascendieron por graves violaciones al debido proceso, a fin de detectar errores, encontrar culpables y procurar correcciones en la medida en que fuera posible. En Argentina, por ejemplo, se instituyó la Comisión de la Verdad en el 1986; en Chile en 1991; en Perú en el 2003; y en Ecuador en el 2007.

En Argentina, la Comisión de la Verdad se instauró principalmente para investigar los crímenes de la dictadura militar argentina, la cual derrocó el gobierno constitucional de la presidenta María Estela Martínez de Perón. Esta dictadura, ocurrida desde el 24 de marzo de 1976 hasta el 10 de diciembre de 1983, se caracterizó por cruentas violaciones a los derechos humanos y crímenes de lesa humanidad. Esta comisión fue una de las primeras en el mundo, convirtiéndose en modelo y patrón de iniciativa de casi todas las demás naciones latinoamericanas y algunas otras en el mundo entero que adoptaron este procedimiento. ${ }^{25}$

En Chile, repercutió mucho lo ocurrido después del golpe de Estado al presidente Salvador Allende, ocurrido el 11 de septiembre de 1973, en circunstancias en que la propia Corte Suprema de dicha nación se reunió en pleno y respaldó el golpe militar, a fin de salvaguardar la seguridad nacional, considerando además que tal posición resultó un acierto para las aspiraciones generales del pueblo chileno. Esta comisión contribuyó al esclarecimiento global de lo ocurrido entre el 11 de septiembre de 1973 y el 11 de marzo de 1990, periodo en el que muchas personas perdieron la vida víctimas de discriminación y violación política. ${ }^{26}$

En Perú, se creó la Comisión de la Verdad y Reconciliación para investigar y esclarecer las graves violaciones a los derechos humanos ocurridas entre 1980 y el 2000, durante el conflicto armado interno y el régimen encabezado por el expresidente Alberto Fujimori. En dicho país, hubo agrupaciones de extrema izquierda lideradas por Sendero Luminoso que proliferaron en las zonas rurales del país. Las comunidades rurales y los pueblos indígenas y amazónicos fueron los más afectados por esta ola de terror y de tortura. Posteriormente, durante el régimen del expresidente Fujimori se promulgaron leyes de amnistía e impunidad a los escuadrones de la muerte creados por el gobierno para contrarrestar a los grupos rebeldes. ${ }^{27}$

En Ecuador, la Comisión de la Verdad se creó para investigar violaciones a los derechos humanos ocurridos entre 1984 y el 2008, siendo la mayor concentración de vulneraciones y atropellos contra la dignidad humana en el gobierno del expresidente León Febres-Cordero. La criminalización de los enemigos políticos y la generalización del concepto de enemigo a todas las formas de oposición, implicó que la dignidad humana fuese un valor precario durante ese gobierno. La estrategia aplicada por el régimen de Febres-Cordero para desarticular los grupos insurgentes en el país, aniquilar a su dirigencia y reprimir a la oposición política, se sustentó en el uso de estructuras especiales, tanto de la Policía, como de las Fuerzas Armadas. ${ }^{28}$

\footnotetext{
25. Cf. Dorys Ardila Muñoz. Comisiones de la verdad en América Latina. (1996). Págs. 2 y 3.

26. Véase Victor José Castellanos, supra, nota 24. Pág. 4.

27. Cf. Ardila-Muñoz, supra, nota 25. Págs. 8-12.

28. Véase Comisión de la Verdad E. (2010). Sin Verdad No HaY justicia. Resumen Ejecutivo. Disponible en http://www.alfonsozambrano.com/comision_verdad/cdv10-informe_final.pdf
} 
Debido al modelo de administración de justicia de los países de la región de estas épocas, los jueces no contaban con la independencia judicial suficiente para investigar todos los casos en los que se denunciaban violaciones, torturas, persecuciones, atentados contra la vida, detenciones arbitrarias y desapariciones forzadas, entre muchos otros. Cuando aparecía un juez con la entereza de investigar y llegar al esclarecimiento de determinados sucesos, inmediatamente era sujeto de presiones o de decisiones disciplinarias que le impedían continuar con estos intentos. Muchas leyes de amnistía coartaban la independencia de los jueces, al regular que aquellos crímenes perpetrados por disposiciones de los propios gobiernos en el combate a la subversión estarían excluidos de la justicia penal $y$, en consecuencia, ningún juez podía tener facultades o competencias para juzgar tales hechos.

Desde principios de la década los noventa, los países de América Latina han implementado numerosas reformas judiciales. Estas estuvieron guiadas por el propósito de mejorar la eficiencia de los procesos judiciales, aumentar el acceso a la justicia y promover la independencia judicial. Sin embargo, todavía persisten serios problemas de eficiencia, acceso e independencia. Una de las áreas más problemáticas es la de la administración de las políticas públicas de justicia, la cual comprende todas aquellas decisiones destinadas a elaborar, gestionar e implementar el presupuesto judicial, así como las destinadas a elaborar, coordinar e implementar las políticas de recursos humanos, $y$, finalmente, las contrataciones de bienes y servicios (distribución de causas, estadísticas, notificaciones, información general, limpieza y restauración de bienes, entre otras). El problema reside en que no existe un adecuado control ciudadano y parlamentario sobre la administración de las políticas públicas de justicia.

En la región existen dos modelos básicos para la administración de las políticas públicas de justicia. ${ }^{29}$ Los colegios de la judicatura encargados de buena parte de las actividades administrativas (Argentina, Colombia, Bolivia, Brasil y Ecuador con matices), demasiado numerosos, cuyos miembros se desempeñan en otros cargos (no tienen dedicación exclusiva), con presidentes que duran pocos años en sus funciones (normalmente dos años), y a los que no se les requiere tener experiencia en técnicas de administración

29. Sebastián Linares. La administración de las politicas de jus ticia en América Latina: nuevos horizontes de reforma. REVISTA iberoamericana viII(31). Septiembre de 2008. Págs. 173-174. Disponible en http://www.iai.spk-berlin.de/fileadmin/dokumentenbibliothek/Iberoamericana/2008/Nr_31/31_Linares.pdf pública. El otro modelo vigente en América Latina son las cortes supremas, cuya estructura tampoco es eficiente: sus miembros no suelen tener experiencia en técnicas de gestión, sus presidentes duran también pocos años, y tienen múltiples funciones a cargo.

Por otra parte, en los colegios de la judicatura, la responsabilidad política de sus miembros está o bien vagamente delineada (no resulta claro cómo pueden ser destituidos ante una gestión ineficiente), o bien se exige un proceso de juicio político muy costoso, el cual requiere la denuncia de irregularidades o ilícitos en el ejercicio de la función y la intervención de órganos políticos y mayorías cualificadas. Esta estructura es claramente ineficiente para la elaboración y ejecución de políticas públicas de largo plazo. ${ }^{30}$

En las cortes supremas, la responsabilidad final de la administración recae fundamentalmente en el presidente de la Corte, quien tiene el control de la agenda (él decide qué temas deben tratarse). Sin embargo, no se le exigen al presidente conocimientos especiales en técnicas de administración pública, además de que este suele durar pocos años en su función (normalmente la presidencia dura dos años y es rotativa). Su elección, por otra parte, es a puerta cerrada por mayoría de votos (salvo en El Salvador, país en donde el presidente de la Corte lo elige la Asamblea cada vez que se renuevan cargos a la magistratura). Esta forma de organización resulta contraproducente para la elaboración de políticas eficientes y de largo plazo. $^{31}$

A manera de resumen, coincidimos con Sebastián Linares en que la búsqueda de la eficiencia organizativa y la rendición de cuentas en la administración de las políticas públicas judiciales, en América Latina, es una cuestión subalterna, en parte debido a una cultura política que privilegia el clientelismo y a una cultura jurídica que pone el acento en el formalismo. A ello se le suma una concepción normativa distorsionada de la independencia judicial, la cual no diferencia entre el aspecto administrativo de la organización judicial y el aspecto jurisdiccional. Sin duda, ha habido grandes avances en la organización de la justicia desde la tercera ola de democratización, pero la cuestión de la eficiencia y la rendición de cuentas democrática sigue siendo una cuenta pendiente. ${ }^{32}$

Como resultado de las reformas, los poderes judiciales:

\footnotetext{
30. Id. Pág. 173

31. Id.

32. Id. Pág. 175 .
} 
Hoy muestran una posición muy mejorada, tanto por las competencias que han ganado - algunas en temas altamente relevantes desde el punto de vista público-, como por las dimensiones que han adquirido las instituciones judiciales $y$, por ende, la cantidad de recursos públicos de los que disponen. Tratándose de instituciones altamente jerarquizadas, como son los Poderes Judiciales de la región, esta mayor importancia y el peso específico ganado por los tribunales han redundado particularmente en mayor poder para sus cúpulas. Las Cortes aumentaron su poder como fruto del traspaso o asignación de nuevas competencias. (...)

Lo que antes era parte de la institucionalidad política normal, hoy se encuentra más bien como situaciones que, sin dejar de ser preocupantes, son claramente excepcionales. Esto no quiere decir que no existan mecanismos de presión sobre los integrantes de las cortes supremas de la región, pero sí es difícil que estos revistan el carácter burdo y grosero que antaño los caracterizó. Lamentablemente, la falta de transparencia en muchas de las actuaciones judiciales todavía genera espacios para esas presiones. ${ }^{33}$

\section{LA INDEPENDENCIA JUDICIAL COMO GARANTÍA DEL DEBIDO PROCESO}

El debido proceso es un principio jurídico procesal que consiste en dotar a las personas de ciertas garantías o derechos mínimos, básicos o elementales, con el propósito de asegurar un resultado justo y equitativo dentro de todos y cada uno de los procesos que se sustancien en las cortes de justicia. ${ }^{34}$ Constituye, además, una salvaguarda para asegurar una justicia más rápida y expedita.

Tiene su génesis en el denominado dueprocess of law del derecho anglosajón, y está compuesto por el debido proceso sustantivo, el cual tutela a los ciudadanos de normas o leyes contrarias a los derechos fundamentales, y el debido proceso adjetivo, que proclama las garantías procesales que permiten hacer efectivos los derechos fundamentales.

El debido proceso legal (lato sensu) es un conjunto no solo de procedimientos legislativos, judiciales y administrativos que deben jurídicamente

33. Véase Juan Enrique Vargas-Viancos. Las Cortes Supremas y la reforma judicial en Latinoamérica. Sistemas Judiciales. 2008. Págs. 17-18, 30. Disponible: http://www.sistemasjudiciales.org/ content/jud/archivos/revpdf/39.pdf

34. Véase Omar Huertas et al., supra, nota 3. cumplirse para que una ley, sentencia o resolución administrativa que se refiera a la libertad individual sea formalmente válida (aspecto adjetivo del debido proceso), sino también para que consagre una debida justicia en cuanto no lesione indebidamente cierta dosis de libertad jurídica presupuesta como intangible para el individuo en el Estado que se trate (aspecto sustantivo del debido proceso). ${ }^{35}$

El debido proceso constituye un postulado esencial y primordial de un Estado de derechos. ${ }^{36}$ Esto significa, en buen romance, el derecho de los ciudadanos a exigir de las actuaciones de los jueces un respeto severo, riguroso e irrestricto de las normas jurídicas y de las formas que conlleve cada procedimiento. En suma, hablar de debido proceso es referirnos a la expresión máxima de las garantías fundamentales categorizadas como derechos humanos.

El debido proceso se divide en adjetivo que es el conjunto de reglas y procedimientos que el legislador y el poder ejecutivo deben cumplir al dictar leyes y reglamentos, que regulan jurídicamente la conducta de los individuos y restringen la libertad civil, y en sustantivo, que se define como un standard de justicia que determina a aquellos órganos hasta dónde pueden incidir en el ejercicio del arbitrio que las constituciones les atribuye, sobre la libertad individual. ${ }^{37}$

No obstante, aunque hablar de debido proceso equivale a tratar de derechos humanos, no se deben restringir estas reglas exclusivamente para aquellos procesos en que estén involucradas personas naturales, pues también favorecen los derechos de personas jurídicas vinculadas en procesos judiciales, independiente de su naturaleza pública o privada. Las personas jurídicas también pueden ser titulares de ciertos derechos fundamentales, entre ellos, precisamente, la independencia de los jueces.

El debido proceso, como su nombre lo indica, es común a todo tipo de procesos judiciales, sin importar la materia de que se trate, como también a todo tipo de procedimiento administrativo, esto es, están constreñidos a aplicar y respetar tales garantías, no solo las autoridades judiciales, sino también las administrativas. ${ }^{38}$ De ahí que el debido proceso no se limita exclusivamente a las formalidades de un

\footnotetext{
35. Cf. Juan Francisco Linares. RAzONABILIDAD DE LAS LEYES. EL DEBIDO PROCESO COMO GARANTÍA INNOMINADA EN LA Constitución Argentina. Astrea. (1970). Pág. 11.

36. Véase Omar Huertas et al., supra, nota 3.

37. Véase Cecilia Gilardi-Madariaga. Acerca del principio de razonabilidad y el debido proceso. Revista Pensamiento Penal. Noviembre 2015. Pág. 184. Disponible en http://www.pensamientopenal.com.ar/system/files/2015/11/doctrina42463.pdf

38. Véase Omar Huertas et al., supra, nota 3.
} 
proceso judicial, sino que procura además el cumplimiento de todos los requerimientos, exigencias y normas de orden público que pudieren existir en todos los procedimientos, judiciales o administrativos, a efecto de que los ciudadanos puedan hacer respetar sus derechos ante cualquier autoridad de gobierno.

La importancia, sin lugar a dudas, del debido proceso, no es solo enunciativa, sino que se constituye como eje rector de los procesos ajustados a derecho y que son parte fundamental para el Estado de derecho, la cual es justamente la pretensión; no solo ponderar esta máxima en su norma, sino que sea parte de su realidad jurídica. ${ }^{39}$

La Corte Constitucional colombiana, en la Sentencia C-475/97, al referirse al alcance del debido proceso lo ha definido como un derecho de estructura compleja que se compone de un conjunto de reglas y principios que, articulados, garantizan que la acción punitiva del Estado no resulte arbitraria. Algunas de las reglas constitucionales que configuran este derecho son de aplicación inmediata y anulan cualquier norma que las limite o restrinja. Así, por ejemplo, el derecho a la legalidad del delito y de la pena no admite restricción ninguna, como tampoco el principio de la no reformatio in pejus, o el principio de favorabilidad..$^{40}$

$\mathrm{Al}$ respecto, la sentencia precisa que, no obstante, otros de los elementos integrantes del debido proceso tienen la estructura lógica de estándares o reglas que deben ser aplicadas prima facie, y admiten ponderaciones o limitaciones útiles, necesarias y proporcionadas para asegurar la vigencia de otro derecho fundamental o de un interés constitucional de igual entidad. En particular, el derecho de defensa es uno de aquellos derechos que plantea parámetros de actuación que deben ser regulados por el legislador garantizando su máxima aplicación, pero cuidándose de afectar otros derechos o bienes constitucionalmente valiosos que se encuentran en juego en el juicio penal o administrativo. ${ }^{41}$

En similar sentido, la Corte Suprema del Perú señaló, en la Sentencia de Casación 1772-2010, cómo el debido proceso tiene por función asegurar los derechos fundamentales consagrados en la Constitución

39. Véase Yesenia Guadalupe Crespo-Gómez. La JUSTICIA PENAL y SU TRANSICIÓN AL SISTEMA ACUSATORIO EN MÉXICO, AVANCES Y RETROCESOS EN LA REFORMA PROCESAL PENAL LATINOAMERICANA DESDE LA visión México y Cuba. Unijuris. (2016). Pág. 120.

40. Véase Código Penal Colombiano [CPC]. Ley 599 de 2000. Julio 24 de 2000 (Colombia); y Corte Constitucional de Colombia. Sentencia C-475/97. (mp Eduardo Cifuentes Muñoz: Septiembre 25 de 1997).

41. Véase Corte Constitucional de Colombia, supra, nota 40.
Política del Estado, al dar a toda persona la posibilidad de recurrir a la justicia para obtener la tutela jurisdiccional de los derechos individuales por medio de un procedimiento legal en el que se dé oportunidad razonable y suficiente de ser oído, de ejercer el derecho a la defensa, de producir prueba y de obtener una sentencia que decida la causa dentro de un plazo preestablecido en la ley procesal..$^{42}$

La garantía de la independencia debe ser entendida como la autonomía del órgano decisor a la influencia de otros poderes, lo cual, desde Montesquieu, tiende a garantizarse por medio de la división de funciones. Esta garantía requiere mayores cuidados en lo atinente a los órganos judiciales, debido a las presiones políticas de las que pueden ser víctimas los magistrados en el cumplimiento de sus deberes.

A fin de prevenirlo, la independencia de los jueces se procura por medio de concursos de antecedentes y oposición para sus nombramientos; límites para las sanciones disciplinarias y/o destitución; intangibilidad de las remuneraciones; e inamovilidad en el cargo. Asimismo, la independencia que se exige, no es solo la de los magistrados, sino también la de todo el sistema de justicia, la cual debe quedar garantizada por medio de la participación del poder judicial y el Ministerio Público en su financiación, sin que tal decisión quede en manos exclusivamente de los otros dos poderes.

En los Comentarios relativos a los Principios de Bangalore sobre la conducta judicial, ${ }^{43}$ al referirse a las condiciones de la independencia judicial, como se afirmó antes, se precisa que, a fin de determinar si la judicatura puede considerarse "independiente" con respecto a los demás poderes del Estado, se ha prestado generalmente atención, entre otras cosas, a la forma de nombramiento de sus miembros, a la duración de sus funciones, a sus condiciones de trabajo, a la existencia de garantías frente a las presiones externas y a la cuestión de si el tribunal exhibe una apariencia de independencia.

La independencia judicial exige tres condiciones mínimas: ${ }^{44}$ (a) seguridad del puesto: vale decir, un nombramiento vitalicio, hasta la edad de jubilación, o por un tiempo determinado, que esté garantizado frente a toda injerencia discrecional o arbitraria del poder ejecutivo u otra autoridad encargada de los

42. Véase Corte Suprema del Perú [Sala Civil Transitoria]. Sentencia de Casación 1772-2010. (Junio 20 del 2011). Pág. 2, considerando segundo.

43. Véase Naciones Unidas. Oficina de las Naciones Unidas contra la Droga y el Delito, supra, nota 6. Págs. 35-36.

44. Id. 
nombramientos; (b) seguridad económica: vale decir, derecho a un sueldo y una pensión establecidos por ley y que no estén sujetos a injerencias arbitrarias del poder ejecutivo que puedan afectar a la independencia judicial. No obstante, dentro de los límites de este requisito, el gobierno puede conservar la facultad de fijar escalas concretas de remuneraciones adecuadas para los diferentes tipos de tribunales. En consecuencia, es posible que diversos sistemas puedan satisfacer del mismo modo el requisito de la seguridad económica, siempre que se proteja la esencia de esta condición; (c) independencia institucional: vale decir, independencia en los asuntos administrativos que guardan relación directa con el ejercicio de sus funciones judiciales. Ninguna fuerza externa debe estar en condiciones de interferir en materias que corresponden directa e inmediatamente a la función decisoria, como, por ejemplo, la asignación de jueces, las audiencias y las listas del tribunal. Aunque necesariamente deban existir algunas relaciones institucionales entre la judicatura y el ejecutivo, esas relaciones no deben interferir en la libertad de la judicatura para resolver las controversias individuales y sustentar la ley y los valores de la constitución.

Otra condición de independencia, definida en la Convención de las Naciones Unidas contra la Corrupción, es la inexistencia de intereses privados que puedan incidir en la decisión. Tal circunstancia se intenta preservar al establecer requisitos de admisibilidad para los cargos, así como al prescribir inhabilidades e incompatibilidades para el ejercicio de estas funciones. ${ }^{45}$

En relación con las interferencias en la función judicial, los Principios de Bangalore sobre la conducta judicial regulan cómo un juez deberá ejercer su función judicial de forma independiente, al partir de su valoración de los hechos y en virtud de una comprensión consciente de la ley, libre de cualquier influencia ajena, de instigaciones, presiones, amenazas o interferencias, sean directas o indirectas, provenientes de cualquier fuente o por cualquier razón. ${ }^{46} \mathrm{La}$ independencia judicial comprende la independencia con respecto a todas las formas de influencia externa.

45. El artículo 6, apartado 2, de la Convención de las Naciones Unidas contra la Corrupción, precisa que cada Estado parte otorgará al órgano o a los órganos mencionados en el párrafo 1 del presente artículo la independencia necesaria, de conformidad con los principios fundamentales de su ordenamiento jurídico, para que puedan desempeñar sus funciones de manera eficaz y sin ninguna influencia indebida. Véase Naciones Unidas. Oficina de las Naciones Unidas contra la Droga y el Delito, supra, nota 6. Pág. 10. 46. Id. Pág. 36.
La confianza en la judicatura se erosiona si se percibe que las decisiones judiciales están sujetas a influencias externas inapropiadas. En aras de la independencia judicial y del mantenimiento de la confianza del público en el sistema de justicia, es fundamental que el ejecutivo, el legislativo y el juez no den la impresión de que las decisiones del juez puedan estar teñidas por esas influencias. Las influencias a que un juez puede verse expuesto son infinitas. Es obligación del juez aplicar la ley tal como la entienda, sobre la base de su valoración de los hechos, sin temor ni favoritismo y sin tener en cuenta si la decisión final puede ser popular o no. ${ }^{47}$

Al responder, por ejemplo, a una presentación en que se señalaba que la sociedad sudafricana no consideraba que la pena de muerte para casos extremos de asesinato fuese un castigo cruel, inhumano o degradante, el presidente del Tribunal Constitucional de Sudáfrica señaló:

La cuestión sometida a nuestra consideración no consiste, sin embargo, en determinar lo que en su mayoría los sudafricanos piensan que debe ser una sentencia adecuada. Es si la Constitución permite esa sentencia. La opinión pública puede tener cierta importancia para la indagación, pero por sí misma no reemplaza el deber depositado en los tribunales de interpretar la Constitución y cumplir sus disposiciones sin temor ni favoritismo. Si la opinión del público fuese decisiva, no se necesitaría un pronunciamiento sobre la constitucionalidad... El tribunal no puede alejarse de su obligación de actuar como árbitro independiente de la Constitución y basar sus decisiones en que han de tener el apoyo del público. ${ }^{48}$

La Convención Interamericana Contra la Corrupción, en su capítulo II, "Medidas preventivas", establece también que, a los fines expuestos en dicho artículo, los Estados parte convienen en considerar la aplicabilidad de medidas, dentro de sus propios sistemas institucionales, destinadas a crear, mantener y fortalecer las normas de conducta para el correcto, honorable y adecuado cumplimiento de las funciones públicas. Estas normas deberán estar orientadas a prevenir conflictos de intereses y asegurar la preservación y el uso adecuado de los recursos asignados a los funcionarios públicos en el desempeño de

\footnotetext{
47. Id.

48. Véase Naciones Unidas, O. C. Convención de las NaCiones Unidas Contra la Corrupción. (2003). Págs. 36-37. Disponible en http://www.unodc.org/pdf/corruption/publications_unodc_convention-s.pdf
} 
sus funciones. Establecerán también las medidas y sistemas que exijan a los funcionarios públicos informar a las autoridades competentes sobre los actos de corrupción en la función pública de los que tengan conocimiento. Tales medidas ayudarán a preservar la confianza en la integridad de los funcionarios públicos y en la gestión pública. ${ }^{49}$

En cuanto a la imparcialidad, la Corte Interamericana de Derechos Humanos, ${ }^{50}$ citando una jurisprudencia de la Corte Europea de Derechos Humanos, ha dicho que esta es una característica de todo órgano decisor, y que "no basta con serlo sino que también debe parecerlo", por lo que habrá de entendérsela en este doble carácter. ${ }^{51}$ Así, desde el punto de vista subjetivo, comprenderá la ausencia de prejuicios e intereses personales con relación a las partes de un litigio que pudieran afectar la objetividad y neutralidad del pronunciamiento.

La sentencia precisa que la Corte Europea de Derechos Humanos ha señalado cómo la imparcialidad tiene aspectos, tanto subjetivos, como objetivos, a saber: (1) el tribunal debe carecer, de una manera subjetiva, de prejuicio personal; (2) también debe ser imparcial desde un punto de vista objetivo, es decir, debe ofrecer garantías suficientes para que no haya duda legítima al respecto. Bajo el análisis objetivo, se debe determinar si, aparte del comportamiento personal de los jueces, existen hechos averiguables que podrán suscitar dudas respecto de su imparcialidad. En este sentido, hasta las apariencias podrán tener cierta importancia. Lo que está en juego es la confianza que deben inspirar los tribunales a los ciudadanos en una sociedad democrática y, sobre todo, en las partes del caso. ${ }^{52}$

Tradicionalmente, esta garantía se ha intentado proteger mediante normas procesales que regulan los institutos de la recusación e inhibitoria. A su vez, desde el punto de vista objetivo, la imparcialidad debe ser un hecho que resulte convincente y brinde confianza a la población en la institución judicial. En este sentido, y tal como lo sostuvo el Tribunal Europeo de Derechos Humanos, hasta las apariencias

49. Id.

50. Cf. Omar Huertas Díaz, Víctor Cáceres Tovar, Natalia Chacón Triana, Waldina Gómez Carmona. Convención Americana DE Derechos Humanos. Doctrina y Jurisprudencia 1980-2005. Grupo Editorial Ibáñez. (2005).

51. Véase Corte Interamericana de Derechos Humanos. (Caso Herrera Ulloa vs. Costa Rica). Excepciones Preliminares, Fondo, Reparaciones y Costas. San José, Costa Rica. (Sentencia de 2 de julio de 2004). Pág. 83. Disponible en http://www.corteidh.or.cr/ docs/casos/articulos/seriec_107_esp.pdf

52. Id. podrán tener importancia: "Justice must not only be done: It must also be seen to be done".$^{53}$

La teoría de la apariencia fue formulada originariamente en Inglaterra en 1924, en el caso "R. Vs. Sussex". Un motorista llamado McCarthy fue procesado por un accidente. El secretario del tribunal resultó ser miembro del bufete de abogados que había demandado al acusado. Los jueces condenaron a McCarthy quien, al enterarse de las vinculaciones del secretario, pidió que se anulara el fallo. Los magistrados debieron jurar que habían adoptado su decisión sin haber consultado ni haber sido influenciados por el secretario. A raíz de ese caso, quedó claro que las decisiones de los tribunales, como la mujer del César, no solo deben ser justas, sino también parecerlas. ${ }^{54}$

Los últimos pronunciamientos de la Corte Interamericana ${ }^{55}$ enfatizan que la independencia judicial es uno de los pilares básicos de las garantías del debido proceso, por lo cual debe ser respetada en cualquier clase de procedimiento y ante todas las instancias procesales en que se decida sobre los derechos de la persona. Así, inclusive tratándose de peticiones de amnistía, indulto o conmutación de la pena de los condenados a muerte ${ }^{56}$, la Corte Interamericana ${ }^{57}$ exige que se tramiten mediante procedimientos imparciales y adecuados en los que se respeten las garantías del debido proceso legal, consagradas en el primer

53. Véase F. J. Arroyo-Ferrer. El debido proceso desde la perspectiva de la Corte Interamericana de Derechos Humanos. Revista Jurídica de la Universidad de Palermo 14(1). Pág. 170. Disponible en http://www.palermo.edu/derecho/revista_juridica/ pub-14/Revista_Juridica_Ano14-N1_06.pdf

54. El País. La buena "apariencia" de la justicia. El PAís. (Junio 1 del 2011). Pág. 2. Disponible en http://politica.elpais.com/politica/2011/06/01/actualidad/1306940253_929368.html

55. Cf. Omar Huertas et al., supra, nota 50.

56. "Párrafo 186: En el presente caso, la Corte estima que las peticiones individuales de clemencia previstas en la Constitución, deben ejercerse mediante procedimientos imparciales y adecuados, de conformidad con el artículo 4.6 de la Convención, en combinación con las disposiciones relevantes de ésta acerca de las garantías del debido proceso establecidas en el artículo 8. Es decir, no se trata solamente de interponer formalmente una petición, sino de tramitarla de conformidad con el procedimiento que la torne efectiva. Véase Corte Interamericana de Derechos Humanos. (Caso Hilaire, Constantine y Benjamin y otros vs. Trinidad y Tobago). Fondo, Reparaciones y Costas. Serie C. San José, Costa Rica. (Sentencia de 21 de junio de 2002). Pág. 63. Disponible en http://www.corteidh. or.cr/docs/casos/articulos/seriec_94_esp.pdf

57. Cf. Omar Huertas Díaz, Víctor Cáceres Tovar, Natalia Chacón Triana, Waldina Gómez Carmona, Eduardo Castellanos Roso, José Alfredo Sanabria. Colombia ante la Corte Interamericana de Derechos Humanos-Recuperación de la Memoria HistóRICA 1995-2006. Grupo Editorial Ibáñez. (2006). 
párrafo del artículo $8^{\circ}$ de la Convención Americana de Derechos Humanos. ${ }^{58}$

En un fallo del 30 de junio del 2009, la Corte Interamericana integró a su doctrina jurisprudencial la de la Corte Europea de Derechos Humanos, ${ }^{59}$ así como también los principios básicos de las Naciones Unidas relativos a la independencia de la judicatura. Concluyó que el derecho al juez o tribunal independiente comprende los siguientes mecanismos de protección: un adecuado proceso de nombramiento; ${ }^{60}$ la

58. "Artículo 8. Garantías Judiciales. 1. Toda persona tiene derecho a ser oída, con las debidas garantías y dentro de un plazo razonable, por un juez o tribunal competente, independiente e imparcial, establecido con anterioridad por la ley, en la sustanciación de cualquier acusación penal formulada contra ella, o para la determinación de sus derechos y obligaciones de orden civil, laboral, fiscal o de cualquier otro carácter". Véase Organización de los Estados Americanos, supra, nota 7. Pág. 4.

59. "Párrafo 70: Conforme a la jurisprudencia de esta Corte y de la Corte Europea, así como de conformidad con los Principios básicos de las Naciones Unidas relativos a la independencia de la judicatura (en adelante "Principios Básicos"), las siguientes garantías se derivan de la independencia judicial: un adecuado proceso de nombramiento, la inamovilidad en el cargo y la garantía contra presiones externas. Párrafo 146: El artículo 8.1 de la Convención Americana de Derechos Humanos, reconoce que ' $[t]$ oda persona tiene derecho a ser oída (...) por un juez o tribunal (...) independiente’. Los términos en que está redactado este artículo indican que el sujeto del derecho es el justiciable, la persona situada frente al juez que resolverá la causa que se le ha sometido. De ese derecho surgen dos obligaciones. La primera del juez y la segunda del Estado. El juez tiene el deber de ser independiente, deber que cumple cuando juzga únicamente conforme $\mathrm{a}-\mathrm{y}$ movido por- el Derecho. Por su parte, el Estado tiene el deber de respetar y garantizar, conforme al artículo 1.1 de la Convención, el derecho a ser juzgado por un juez independiente. El deber de respeto consiste en la obligación negativa de las autoridades públicas de abstenerse de realizar injerencias indebidas en el Poder Judicial o en sus integrantes, es decir, con relación a la persona del juez específico. El deber de garantía consiste en prevenir dichas injerencias e investigar y sancionar a quienes las cometan. Además, el deber de prevención consiste en la adopción, conforme al artículo 2 de la Convención, de un apropiado marco normativo que asegure un adecuado proceso de nombramiento, la inamovilidad de los jueces y las demás condiciones ya analizadas en el Capítulo vi de la presente Sentencia”. Véase Corte Interamericana de Derechos Humanos. (Caso Reverón Trujillo vs. Venezuela). Serie C. San José, Costa Rica. (Sentencia del 30 de junio de 2009). Pág. 20. Disponible en http://www.corteidh.or.cr/docs/ casos/articulos/seriec_197_esp.pdf

60. Véase Corte Interamericana de Derechos Humanos. (Caso del Tribunal Constitucional vs. Perú). San José, Costa Rica. (Sentencia del 31 de enero del 2001). Pág. 79. Dsiponible en http://www.cor teidh.or.cr/docs/casos/articulos/Seriec_71_esp.pdf; véase también Corte Interamericana de Derechos Humanos. (Caso Palamara Iribarne vs. Chile). San José, Costa Rica. (Sentencia del 22 de noviembre del 2005). Párr. 156, pág. 79: "Segunda parte: La independencia de cualquier juez supone que se cuente con un adecuado proceso de nombramiento, con una duración establecida en el cargo, garantías de inamovilidad y con una garantía contra presiones externas". inamovilidad en el cargo ${ }^{61}$ y la garantía contra presiones externas. ${ }^{62}$

La doctrina jurisprudencial de la Corte Interamericana ha definido que los procedimientos para el nombramiento de jueces que satisfacen las condiciones que exige la Convención para la implementación de un verdadero régimen judicial independiente deben poseer las siguientes características: ${ }^{63}$ (a) asegurar la igualdad de oportunidades en el acceso al Poder Judicial mediante una libre concurrencia, de tal forma que todos los ciudadanos que acrediten los requisitos determinados en ley puedan participar en los procesos de selección sin ser objeto de tratos desiguales arbitrarios; (b) todos los aspirantes deben de concursar en igualdad de condiciones, aun con respecto a quienes ocupan cargos provisionales, los cuales no podrán recibir privilegios, ventajas, o en su caso, desventajas en relación con el cargo que ocupan y al cual aspiran; (c) no son admisibles restricciones que impidan o dificulten a quien no forma parte de la administración o de alguna entidad llegar al servicio con base en sus méritos; (d) señalamiento ampliamente público, claro y transparente de los requisitos exigidos para el desempeño del cargo; (e) deben tener en cuenta la singularidad y especificidad de las funciones que se van a desempeñar; (f) la decisión que pone fin al procedimiento debe sustentarse en parámetros básicos de objetividad y razonabilidad con base en los méritos y calidades del aspirante; (g) el diseño del procedimiento debe establecer forzosamente un bajo grado de discrecionalidad en la selección del personal judicial de carrera, a fin de evitar que se escojan personas que no son las más idóneas.

En el número 10 de los principios básicos relativos a la independencia de la judicatura, se señala que las personas seleccionadas para ocupar cargos judiciales serán personas íntegras e idóneas, y tendrán la formación o las calificaciones jurídicas apropiadas. Todo método utilizado en la selección de personal judicial garantizará que este no sea nombrado por motivos indebidos. En la selección de los jueces, no

61. Véase Corte Interamericana de Derechos Humanos. (Caso del Tribunal Constitucional vs. Perú), supra, nota 60. Pág. 42, párr. 75. 62. NA: Recogidos en los principios 2, 3 y 4 . Véase Naciones Unidas. Oficina del Alto Comisionado. Principios básicos RelaTivos a la INDEPENDENCIA DE LA JUdicatura. (Septiembre 6 de 1985). Disponible en https://www.ohchr.org/sp/professionalinterest/pages/independencejudiciary.aspx

63. Cf. Daniel Delgado-Ávila. (2011). El derecho fundamental al juez independiente en la jurisprudencia de la Corte Interamericana de Derechos Humanos. Anuario mexicano de Derecho interNACiONAL 11. Enero del 2011. Pág. 308. Dsiponible en http://www. scielo.org.mx/pdf/amdi/v11/v11a10.pdf 
se hará discriminación alguna por motivo de raza, color, sexo, religión, opinión política o de otra índole, origen nacional o social, posición económica, nacimiento o condición; el requisito de que los postulantes a cargos judiciales sean nacionales del país del que se trate no se considerará discriminatorio. ${ }^{64}$

Respecto al requisito de la inamovilidad en el cargo, la Corte Interamericana ha manifestado que se trata de una garantía de la independencia judicial, la cual, a su vez, se compone por las siguientes garantías: permanencia en el cargo, un proceso de ascensos adecuado y no despido injustificado o libre remoción. Quiere decir esto que si el Estado incumple una de estas garantías, afecta la inamovilidad y, por tanto, no está cumpliendo con su obligación de garantizar la independencia judicial. ${ }^{65}$ En el caso Palamara Iribarne vs. Chile, ${ }^{66}$ estimó que la estructura orgánica y la composición de los tribunales militares suponen que, en general, sus integrantes sean militares en servicio activo, estén subordinados jerárquicamente a los superiores por medio de la cadena de mando, su nombramiento no dependa de su competencia profesional e idoneidad para ejercer las funciones judiciales, no cuenten con garantías suficientes de inamovilidad y no posean una formación jurídica exigible para desempeñar el cargo de juez o fiscales. Todo ello lleva a que dichos tribunales carezcan de independencia e imparcialidad.

El número 12 de los principios básicos relativos a la independencia de la judicatura establece que se garantizará la inamovilidad de los jueces, tanto de los nombrados mediante decisión administrativa, como de los elegidos, hasta que cumplan la edad para la jubilación forzosa o expire el periodo para el que hayan sido nombrados o elegidos, cuando existan normas al respecto. ${ }^{67}$

La garantía contra presiones externas fue analizada por la Corte Interamericana, entre otros casos, en el de Reverón Trujillo vs. Venezuela ${ }^{68}$ en el cual

64. Véase Naciones Unidas. Oficina del Alto Comisionado, supra, nota 62.

65. Véase Corte Interamericana de Derechos Humanos, supra, nota 59. Pág. 4.

66. Véase Corte Interamericana de Derechos Humanos, supra, nota 60. Págs. 78 y 79, párr. 155 .

67. Véase Naciones Unidas. Oficina del Alto Comisionado, supra, nota 62 .

68. "Párrafo 117: La inamovilidad de los jueces provisorios está estrechamente ligada a la garantía contra presiones externas, ya que si los jueces provisorios no tienen la seguridad de permanencia durante un período determinado, serán vulnerables a presiones de diferentes sectores, principalmente de quienes tienen la facultad de decidir sobre destituciones o ascensos en el Poder Judicial. Párrafo 118: Esta Corte ha sostenido que los nombramientos provisionales precisa cómo los jueces cuentan con varias garantías que refuerzan su estabilidad en el cargo con miras a garantizar la independencia de ellos mismos y del sistema, así como también la apariencia de independencia frente al justiciable y la sociedad. Asimismo, la garantía de inamovilidad debe operar para permitir el reintegro a la condición de magistrado de quien fue arbitrariamente privado de ella, porque de lo contrario los Estados podrían remover a los jueces e intervenir de ese modo en el Poder Judicial sin mayores costos o control. Por tanto, un recurso que declara la nulidad de una destitución de un juez por no haber sido ajustada a la ley debe llevar necesariamente a la reincorporación. En el Caso del Tribunal Constitucional del 2001 (Aguirre-Roca, Rey-Terry y Revoredo-Marsano vs. Perú), ${ }^{69}$ en el que señala que el juicio político contemplado en la Constitución peruana no puede emplearse para controlar el ejercicio de la jurisdicción del Tribunal Constitucional, ni para ejercer presión contra sus magistrados, pues ello constituiría, como efectivamente sucedió, una interferencia ilegítima en la función de los jueces, lo que debilitaría el sistema democrático de gobierno.

En el inciso e, del párrafo 64, señala, además:

La destitución de los magistrados estuvo motivada en la presunta irregularidad en la tramitación de la aclaratoria solicitada de la sentencia que declaró inaplicable la Ley No. 26.657, bajo la argumentación de que era un acto que debía conocer el pleno del Tribunal Constitucional. Esta decisión fue tomada tanto por la Comisión Investigadora como por la Subcomisión Acusadora, pese a la existencia de un mandato expreso que impedía controlar o revisar las decisiones jurisdiccionales del Tribunal Constitucional. Con esta actuación incurrieron en abuso y desviación de poder, y violentaron el principio de independencia y autonomía del Tribunal Constitucional consagrado en la Convención y la Constitución peruana. ${ }^{70}$

En el inciso g, se precisa además: “El trámite seguido por la Comisión Investigadora del Congreso violentó el debido proceso en razón de que dicha

deben constituir una situación de excepción y no la regla, ya que la extensión en el tiempo de la provisionalidad de los jueces o el hecho de que la mayoría de los jueces se encuentren en dicha situación, generan importantes obstáculos para la independencia judicial". Véase Corte Interamericana de Derechos Humanos, supra, nota 59. Pág. 35.

69. Véase Corte Interamericana de Derechos Humanos. (Caso del Tribunal Constitucional vs. Perú), supra, nota 60. Pág. 3, párr. 64, apartado d.

70. Id. 
Comisión fue creada para examinar hechos denunciados por la magistrada Revoredo sobre la sustracción de documentos del Tribunal Constitucional y no para revisar actos jurisdiccionales de dicho Tribunal".71

Al analizar la relación coetánea de la independencia con las demás garantías del debido proceso, se encuentra que esta es el punto de partida para cumplir con las exigencias formales o procedimentales de un juicio, tales como el derecho a la contradicción, a ser oídos, a la motivación, a contar con jueces naturales, al doble conforme y a un plazo razonable, entre otros. Asimismo, para asegurar el cumplimiento de las exigencias de índole material, relacionadas con la preservación de los criterios de justicia del juzgador al momento de adoptar una decisión, tales como la razonabilidad, la ponderación, la proporcionalidad o la equidad.

También el debido proceso, entre sus múltiples manifestaciones, tiene la tarea de regir los procedimientos - administrativos- de instauración de independencia de la judicatura en un país, esto es, asegurar un adecuado proceso de nombramiento de los jueces, su inamovilidad en los cargos, y dotarlos de garantías contra presiones externas. La existencia de un proceso adecuado de nombramientos enseña que la selección de jueces debe sostenerse en principios tales como la integridad, la aptitud e idoneidad, así como en criterios objetivos tales como los méritos personales, la preparación académica y la formación jurídica, de modo que se asegure una igualdad de oportunidades y la implementación de un sistema independiente de elección de jueces.

En la actualidad, cuenta con reconocimiento universal la definición según la cual los procesos disciplinarios que se sustancian en contra de funcionarios judiciales deben respetar las garantías del debido proceso, al existir únicamente la posibilidad de destituir, remover o suspender a un juez en sus funciones por motivos debidamente fundados y causales preexistentes en las normas orgánicas pertinentes. Por ello, la inamovilidad del cargo de un juez es un principio fundamental a tomar en cuenta en el propósito de precautelar la independencia del poder judicial.

Es claro que la independencia del poder judicial contiene fines sociales y colectivos, pues además de constituir una garantía de la administración de justicia, es un requisito sine qua non para desempeñar la función de juez, quien únicamente puede estar sometido a la Constitución y a la ley. Por medio de la motivación de sus resoluciones, las cuales son públicas y, por tanto, expuestas a la opinión pública, los jueces pueden dar fe de su independencia e imparcialidad.

La transgresión de la independencia judicial implica vulnerar desde su pilar más próximo todo el debido proceso, ${ }^{72}$ lo que repercute en un sentimiento de inseguridad de la ciudadanía en la función judicial, además de falta de confianza y credibilidad en los jueces. Por ello, la importancia de asegurar una justicia independiente, la cual permita trabajar en la cohesión social y recuperar la noción de debido proceso o proceso justo, al identificarlo como un verdadero ente protector de nuestros derechos fundamentales.

Además, el debido proceso constituye una limitante para los gobernantes, autoridades y el Estado en general, como mecanismo legal de restricción de abusos que permite precautelar los derechos, las libertades y los bienes de las personas. En definitiva, obliga a los Estados a someterse a las reglas previstas en el ordenamiento jurídico. Tan importante es el debido proceso como derecho fundamental, que impone también a los Estados el deber de inquirir e indagar a los responsables de violaciones de derechos humanos, procurando la reparación integral de los derechos conculcados.

\section{Conclusiones}

En Latinoamérica, en las últimas dos décadas, se ha forjado la noción de que la independencia judicial es fundamental para la consolidación de la democracia, para la plena vigencia de los derechos humanos y la credibilidad de la ciudadanía en la administración de justicia, de manera que se convierte en un instrumento irrefutable en la restauración del orden social. Es por ello que los países de América Latina, conscientes de esta realidad, han trabajado en los últimos años en mejoras de la justicia, desde los diferentes niveles o esferas en que esta se desarrolla.

En este sentido, se ha trabajado en reformas de leyes para mejorar los sistemas de selección de jueces; en establecer órganos de gobierno autónomos e independientes de la función judicial, denominados "consejos de la judicatura" o "de la magistratura"; en la creación de escuelas judiciales que permitan una capacitación constante de los jueces; en instaurar órganos de defensoría pública en favor de las personas de escasos recursos; en implementar leyes a fin de consolidar una carrera judicial que garantice estabilidad a los judiciales; en incrementar el presupuesto de

72. Véase Omar Huertas et al., supra, nota 3. 
la función judicial y promover el manejo económico autárquico por parte de estos entes, sin intervención de los otros poderes del Estado; en el aumento del salario de los jueces; en garantizar la permanencia inamovible de los jueces durante el tiempo que dure su nombramiento; $y$, en definitiva, en establecer nuevos instrumentos de evaluación, públicos y objetivos, en favor de los servidores judiciales.

En correspondencia con los instrumentos jurídicos internacionales sobre la independencia judicial, el derecho al juez o tribunal independiente comprende los siguientes mecanismos de protección: un adecuado proceso de nombramiento, una duración establecida en el cargo, garantías de inamovilidad y una garantía contra presiones externas.

La independencia judicial como garantía del debido proceso debe estar garantizada por la existencia de tribunales independientes e imparciales, y constituye el núcleo central de un sistema judicial garante de los derechos humanos en plena conformidad con el derecho internacional de los derechos humanos.

En el análisis de estos temas, resulta necesario apreciar también que, al valorarlos integralmente, se debe considerar cómo aún persisten inconvenientes medulares, relacionados con la idiosincrasia y la formación cultural jurídica de estos pueblos, los cuales no distinguen con eficacia la independencia de la función judicial, con independencia de los jueces. En el primer caso, se trata de una garantía del debido proceso; en el segundo, coligada a la primera, el concepto se aproxima más a la imparcialidad judicial.

Por otra parte, crear una justicia demasiado autónoma también suele tergiversar la posición de los más altos magistrados, quienes se suelen resistir ante cualquier posibilidad de rendir cuentas o de dar respuesta a sus acciones, bordeando los límites de la arbitrariedad. No debe renunciarse al control ciudadano y a las decisiones soberanas del pueblo sobre el sistema judicial: las políticas públicas institucionales, en la medida en que no estén dirigidas a alterar decisiones judiciales específicas, en nada lesionan la independencia judicial.

Estas situaciones obligan a las máximas instancias judiciales a realizar evaluaciones periódicas sobre el ejercicio efectivo de la función judicial, concebida como servicio público que exige el mejoramiento de su desempeño para satisfacer las necesidades de la sociedad y los ciudadanos, mediante el diseño de sistemas de rendición de cuentas, gestión de la calidad y de evaluación del desempeño de los jueces. Esto, en la medida en que sean lo suficientemente transparentes, de manera que al propio tiempo que eviten la intromisión en la independencia que les reconoce la ley, para decidir los asuntos que son sometidos a su consideración, eviten, por otra parte, las posibles arbitrariedades, sin dejárselo todo al reconocimiento del derecho al recurrir a las resoluciones judiciales, como garantía del debido proceso.

La Constitución, las leyes y las políticas de un país deben asegurar que el sistema judicial sea verdaderamente independiente de las demás funciones del Estado. Dentro del sistema judicial, los jueces, abogados y fiscales deben tener la libertad de desempeñar sus deberes profesionales sin interferencias y estar protegidos, en el derecho y en la práctica, de todo ataque, acoso y persecución en el desempeño de su actividad profesional en la defensa de los derechos humanos. Deben, por su parte, ser protectores activos de los derechos humanos, responsables ante la población, así como mantener el mayor nivel de integridad en virtud del derecho nacional e internacional y de las normas éticas.

\section{REFERENCIAS}

Asamblea General. Resolución 40/34. DeClaración SOBRE LOS PRINCIPIOS FUNDAMENTALES DE JUSTICIA PARA LAS VÍCTIMAS DE DELITOS Y DEL ABUSO DE PODER. (Noviembre 29 de 1985). Disponible en https://www.unodc.org/pdf/compendium/compendium_2006_es_part_03_02.pdf

Asamblea General. Resolución 40/146. Los DEREChos HUMANOS EN LA ADMINISTRACión DE JUSTICIA. (Diciembre 13 de 1985).

Biblioteca Virtual U. Estatuto DEL JUEZ IBERoAmericANO. (2001). Disponible en http://www.biblioteca.org. ar/libros/211800.pdf

Carlos Ayala-Corao. La independencia de la justicia y los procesos constituyentes en la región andina. EsTUdios Constitucionales 6(1). 2008. Págs. 345-358. Disponible en http://132.248.9.34/hevila/Estudiosconstitucionales/2008/vol6/no1/16.pdf

Cecilia Gilardi-Madariaga. Acerca del principio de razonabilidad y el debido proceso. Revista Pensamiento Penal. Noviembre 2015. Disponible en http://www. pensamientopenal. com.ar/system/files/2015/11/doctrina42463.pdf

Código Penal Colombiano [CPC]. Ley 599 de 2000. Julio 24 de 2000 (Colombia). 
Comisión de la Verdad E. (2010). Sin Verdad No haY JUSTICia. Resumen Ejecutivo. Disponible en http://www. alfonsozambrano.com/comision_verdad/cdv10-informe_final.pdf

Comisión Internacional de Juristas. Principios InTernaCIONALES SOBRE LA INDEPENDENCIA Y RESPONSABILIDAD DE JUECES, ABOGADOS Y FISCALES-GUÍA PARA PROFESIONALES. (2005). Disponible en http://hrlibrary.umn.edu/research/peru-Principios\%20Internacionales $\% 20$ sobre $\% 20$ responsabilidad $\% 20 \mathrm{de} \% 20$ Jueces $\% 20 y \% 20 \% 20$ Fiscales.pdf

Corte Constitucional de Colombia. Sentencia C-475/97. (MP Eduardo Cifuentes Muñoz: Septiembre 25 de 1997).

Corte Interamericana de Derechos Humanos. (Caso del Tribunal Constitucional vs. Perú). San José, Costa Rica. (Sentencia del 31 de enero del 2001). Disponible en http://www.cor teidh.or.cr/docs/casos/articulos/Seriec_71_esp.pdf

Corte Interamericana de Derechos Humanos. (Caso Hilaire, Constantine y Benjamin y otros vs. Trinidad y Tobago). Fondo, Reparaciones y Costas. Serie C. San José, Costa Rica. (Sentencia de 21 de junio de 2002). Disponible en http://www.corteidh.or.cr/ docs/casos/ articulos/seriec_94_esp.pdf (2002).

Corte Interamericana de Derechos Humanos. (Caso Herrera Ulloa vs. Costa Rica). Excepciones Preliminares, Fondo, Reparaciones y Costas. San José, Costa Rica. (Sentencia del 2 de julio del 2004). Disponible en http://www.corteidh.or.cr/docs/ casos/articulos/ seriec_107_esp.pdf

Corte Interamericana de Derechos Humanos. (Caso Palamara Iribarne vs. Chile). San José, Costa Rica. (Sentencia del 22 de noviembre del 2005). Disponible en http://www.corteidh.or.cr/docs/casos/articulos/seriec_135_esp.pdf

Corte Interamericana de Derechos Humanos. (Caso Reverón Trujillo vs. Venezuela). Serie C. San José, Costa Rica. (Sentencia del 30 de junio de 2009). Disponible en http://www.corteidh.or.cr/docs/casos/articulos/seriec_197_esp.pdf

Corte Suprema del Perú [Sala Civil Transitoria]. Sentencia DE CASACión 1772-2010. (Junio 20 del 2011).

Daniel Delgado-Ávila. (2011). El derecho fundamental al juez independiente en la jurisprudencia de la Corte Interamericana de Derechos Humanos. ANUARIO MEXICAno de Derecho internacional 11. Enero del 2011. Págs. 305-329. Dsiponible en http://www.scielo.org. $\mathrm{mx} / \mathrm{pdf} / \mathrm{amdi} / \mathrm{v} 11 / \mathrm{v} 11 \mathrm{a} 10 . \mathrm{pdf}$

Declaración y Programa de Acción de Viena. Conferencia Mundial de Derechos Humanos. Oficina del Alto
Comisionado de las Naciones Unidas para los Derechos Humanos y el Departamento de Información Pública de las Naciones Unidas. (1993).

El País. La buena "apariencia” de la justicia. El PAís. (Junio 1 del 2011). Disponible en http://politica.elpais.com/ politica/2011/06/01/actualidad/1306940253_929368. html

F. J. Arroyo-Ferrer. El debido proceso desde la perspectiva de la Corte Interamericana de Derechos Humanos. Revista Jurídica de la Universidad de PAlermo 14(1). Disponible en http://www.palermo.edu/derecho/revista juridica/pub-14/Revista_Juridica_Ano14-N1_06.

Impunity Watch. Programa Guatemala, Procesos DE ELECCIÓN DE MAGisTrados EN GUATEMALA Y HONDURAs. (2015). Disponible en http://www.impunitywatch.org/docs/32531_IMPUNITY_WATCH_Proceso_eleccion_magistrados_GT_y_HN_TEXTO.pdf

Juan Enrique Vargas-Viancos. Las Cortes Supremas y la reforma judicial en Latinoamérica. Sistemas JudiciaLES. 2008. Disponible: http://www.sistemasjudiciales. org/content/jud/archivos/revpdf/39.pdf

Juan Francisco Linares. Razonabilidad de LAS LeYes. EL DEBIDO PROCESO COMO GARANTÍA INNOMINADA EN la Constitución Argentina. Astrea. (1970).

Naciones Unidas, O. C. Convención de LAs NACIONEs UNIdas Contra la Corrupción. (2003). Disponible en http://www.unodc.org/pdf/corruption/publications unodc_convention-s.pdf

Naciones Unidas, C. L. INFORME DEL RELATOR ESPECIAL LEANDRO DESPOUY SOBRE LA INDEPENDENCIA DE LOS MAgistrados y ABogados. A/HrC/11/41. (Marzo 24 de 2009). Disponible en http://www2.ohchr.org/ english/bodies/hrcouncil/docs/11session/A.HRC.11. 41_sp.pdf

Naciones Unidas. Oficina de las Naciones Unidas contra la Droga y el Delito. Comentario Relativo a los Principios de BANgalore SOBRE LA CONDUCTA JUDICIAL. (2013). Disponible en http://www.unodc.org/ documents/corruption/Publications/2012/V1380121SPAN_eBook.pdf

Naciones Unidas. Oficina del Alto Comisionado. PrINCIPIOS BÁSICOS RELATIVOS A LA INDEPENDENCIA DE LA JUdicatura. (Septiembre 6 de 1985). Disponible en https://www.ohchr.org/sp/professionalinterest/pages/ independencejudiciary.aspx

Omar Huertas Díaz, Víctor Cáceres Tovar, Natalia Chacón Triana, Waldina Gómez Carmona. Convención Americana de Derechos Humanos. Doctrina y JURISPRUDENCIA 1980-2005. Grupo Editorial Ibáñez. (2005) 
Omar Huertas Díaz, Víctor Cáceres Tovar, Natalia Chacón Triana, Waldina Gómez Carmona, Eduardo Castellanos Roso, José Alfredo Sanabria. Colombia ANTE la Corte Interamericana de Derechos HumaNOS-ReCuperación de LA Memoria Histórica 1995-2006. Grupo Editorial Ibáñez. (2006).

Omar Huertas Díaz, Francisco Javier Trujillo Londoño, Luis Gonzalo Lozano Pacheco y José Alfredo Sanabria. EL DERECHO AL DEBIDO PROCESO Y LAS GARANTÍAS JUDICIALES EN LA DIMENSIÓN INTERNACIONAL DE LOS DERECHOS Humanos. Grupo Editorial Ibáñez. (2007).

Organización de los Estados Americanos. Carta DemoCRÁtica INTERAMERICANA. Documentos E INTERPRETACIONES. (2003). Disponible en https://www. oas.org/ oaspage/esp/Publicaciones/CartaDemocratica_spa.pdf

Rubén Remigio Ferro. La independencia judicial y la gestión de la calidad en los tribunales. Justicia y DeRECHO 26 Año 14. 2016.
Sebastián Linares. La administración de las políticas de justicia en América Latina: nuevos horizontes de reforma. REVISTA IBEROAMERICANA VIII(31). Septiembre de 2008. Disponible en http://www.iai.spk-berlin.de/fileadmin/dokumentenbibliothek/Iberoamericana/2008/ Nr_31/31_Linares.pdf

Sir Gerard Brennan. Judicial independence. The AustraLian Judicial Conference, noviembre 2 de 1996, Camberra, Australia. Disponible en http://www.jca. asn.au/wp-content/uploads/ 2014/07/P62_02_09-Judicial-Independence-from-the-Executive-June-2014. pdf

V. J. Castellanos. INForme SOBRE INDEPENDENCIA JUdICIAL en la República Dominicana. (2000). Disponible en http://www.dplf.org/sites/default/files/1184345829. pdf

Yesenia Guadalupe Crespo Gómez. La Justicia PENAL Y SU TRANSICIÓN AL SISTEMA ACUSATORIO EN MÉXICO, AVANCES Y RETROCESOS EN LA REFORMA PROCESAL PENAL LATINOAMERICANA DESDE LA VISIÓN MÉXICO y CuBA. Unijuris. (2016). 